\title{
Evaluation of Mass Loss in Different Stages of Printed Circuit Boards Recycling Employed in Temperature Controllers
}

\author{
Eduardo Luis Schneider ${ }^{a *} \oplus$, Fernando Hamerski ${ }^{a, b} \oplus$, Hugo Marcelo Veit ${ }^{(\oplus,}$, Alex Krummenauer ${ }^{a}($, \\ Marcelo Pilotto Cenci ${ }^{a} @$, Rodrigo de Andrade Chaves ${ }^{c}$,Wagner Luiz Hartmann ${ }^{c}$, Moisés de Mattos Dias ${ }^{c}$, \\ Luiz Carlos Robinson ${ }^{\bullet}{ }^{\circledR}$, Alexandre Silva de Vargas ${ }^{d}$ \\ ${ }^{a}$ Departamento de Engenharia de Materiais, Universidade Federal do Rio Grande do Sul, Av. Bento \\ Gonçalves, 9500, CEP 91509-900, Porto Alegre, RS, Brasil \\ ${ }^{b}$ Instituto do Petróleo e dos Recursos Naturais, Pontifícia Universidade Católica do Rio Grande do Sul, \\ Av. Ipiranga, 6681, CEP 90619-900, Porto Alegre, RS, Brasil \\ 'Instituto de Ciências Exatas e Tecnologias, Universidade Feevale, ERS-239, 2755, Vila Nova, CEP \\ 93525075, Novo Hamburgo, RS, Brasil \\ ${ }^{d}$ DECC, Universidade Federal de Santa Maria, Av. Roraima, 1000, Camobi, CEP 97105-900, Santa \\ Maria, RS, Brasil
}

Received: December 11, 2018; Revised: August 08, 2019; Accepted: September 18, 2019

The aim of this work was to evaluate mass loss in each stage of the recycling process for metal recovery from PCBs of controllers and temperature indicators of cold chambers. The stages of process consists of grinding, particle size classification, magnetic and electrostatic separation. It was analyzed $13 \mathrm{~kg}$ of PCBs. These PCBs were crushed and ground. The ground material were subjected to magnetic and electrostatic separator. The losses in the comminution stages were $12.69 \%$ and are lower than those found in other related works that used mixtures of different types of PCBs, whereas in this work only one model plates were analyzed. $27.2 \%$ absolute mass loss we reached out after particle size separation with Tyler Series with $1 \mathrm{~mm}$ sieve presents the higher mass losses in the whole process and this fraction was not processed as it results in PCBs powder dust that interferes negatively in the electrostatic separation. Comparing the losses in the stages of shredding of PCBs employed in temperature controllers with other studies involving PCBs from the automotive industry and from computers and cell phones, is remarkable that this type of board presents significantly greater potential to be processed for recovery of its materials.

Keywords: Mass losses, PCBs recycling, comminution, magnetic separator, electrostatic separator, temperature controllers.

\section{Introduction}

Waste electrical and electronic equipment (WEEE or e-waste) are in an increasing flow of production and disposal worldwide. With the rapid and exponential technological advance coupled with the consumer desire to always have the most advanced product as well as the planned obsolescence; the electronic products have their life shorter and shorter ${ }^{1,2}$.

In 2016, 44.7 Mt of WEEE was generated worldwide and the projection for 2021 is 52.2 millions of tons, considering an annual increase rate of 3-4 \%. The current proportion of this waste generated per inhabitant is $6.1 \mathrm{~kg} \cdot \mathrm{y}^{-1}$ with a forecast of reaching $6.8 \mathrm{~kg} . \mathrm{y}^{-1}$ until 2021 , and that only $20 \%$ of the total being recycled ${ }^{3}$. The low rate of WEEE recycling is explained by the high cost of the processes. An efficient plant for the extraction and reuse of the valuable materials found in these waste requires high-tech machines, which is a reality only in developed countries. Developing countries, such as Brazil, end up doing partial processing of the waste and exporting these flows ${ }^{4,5}$.

*e-mail: prof.eduardo@ufros.br
In PCBs, which are indispensable for the production as well as the operation of electronic devices, the concentration of valuable metals is usually much higher than that obtained through traditional mining. It is important to highlight the importance of research and development tin the metal recovery from PCB field, since it tends to be simpler, economical in terms of energy, less pollution and results in purer material than the primary sources. In addition, two problems are solved: obtaining valuable metals from secondary sources and reducing the accumulation of waste $\mathrm{e}^{6-8}$

The most advanced e-waste recycling plants use a combination of physical-mechanical and chemical processes for better recovery of valuable metals. A large and unavoidable amount of dust is produced during PCBs comminution procedures. To avoid a large mass loss dust collection systems are used. This prevents dust from being dispersed into the atmosphere or from encrusting into the equipment ${ }^{4}$. Studies show that the powder generated has distinct concentrations of materials according to particle size, and the highest concentrations of valuable metals are found in the smaller particles ${ }^{4}$. 
In this work, PCBs were analyzed, which represent one of the main components of consumer devices, whose lifetime is constantly decreasing, as well as being a source of both hazardous materials for health and the environment, as well as valuable metals and profitable exploitation ${ }^{5,6}$. Considering that studies involving smartphones and computers (e.g. desktops and laptops) have been extensively published ${ }^{9-12}$, it is possible to highlight the relevance of searching for other PCB waste that do not receive so much visibility. The PCBs can also have a significant volume of disposal as well as potential for recycling. The analysis of mass losses is justified by the need to perform the most efficient monitoring of the waste recovery process. In this way, one can assess which processing is most advantageous in recovering valuable metals. The aim of this study is to evaluate the mass losses at each stage of processing for the recovery of valuable metals from PCBs used in controllers and temperature indicators of cold chambers. The mechanical comminution, particle size separation, magnetic and electrostatic separation processes were done in $13 \mathrm{~kg}$ of PCBs. The mass data were collected before and after each step, so that the mass loss could be defined and analyzed at each stage of processing.

\section{Materials and Methods}

A $13 \mathrm{~kg}$ sample of PCBs was used to analyze losses in mass at different stages of the PCBs recycling process. The PCBs were removed from controllers and temperature indicators of cold chambers, donate by Reverse - Waste Management, located in Novo Hamburgo City, Brazil.

The steps of the process are: components removal, comminution, milling $\sim 2 \mathrm{~mm}$, magnetic separation, particle size separation and electrostatic separation. Figure 1 shows a flowchart illustrating all stages of the process.

The electronic components removed were continuous buzzers, with sounding functionality, and electronic connector terminals, used to integrate the inputs and outputs of these PCBs.

The mechanical milling process was done three times in order to fragment the PCBs and facilitate the separation of the materials present in them. It was used a mill (SEIBT, model TS 2X20/600) with work surface of $650 \mathrm{~mm} \times 440 \mathrm{~mm}$ and two three-phase motors of $20 \mathrm{HP}, 60 \mathrm{~Hz}, 4$ poles. After this stage, the granulometric reduction process was continued in a knife mill (SEIBT, model MGHS 1.5/85) with a 2 HP motor, speed of 1125 RPM and using an $8 \mathrm{~mm}$ sieve. Then all the material was processed again with $4 \mathrm{~mm}$ and $2 \mathrm{~mm}$ sieves. This was done to gradually decrease the particle size.

The magnetic separation was carried out in a barrel magnetic separator with $\mathrm{Ne}-\mathrm{Fe}-\mathrm{B}$ magnet with a magnetic field of 4000 Gauss (brand METALMAG, model P with $300 \mathrm{~mm}$ of barrel diameter and $254 \mathrm{~mm}$ of width of the barrel magnetic face) with the angle of magnetic circuit adjustment at $0^{\circ}$.
The particle size separation process was performed with the objective of improving the efficiency of the electrostatic separation. A Tyler Series with $1 \mathrm{~mm}$ sieve was used to remove particles smaller than $1 \mathrm{~mm}$. These particles smaller than $1 \mathrm{~mm}$ easily disperse, reducing the efficiency of the electrostatic separation process. The particle size between 1 - $2 \mathrm{~mm}$ was sent to electrostatic separation.

A corona electrostatic separator-CES - (INBRAS-ERIEZ, model ESP-14/01S) was used with the following operating conditions: $\alpha$-Ionizing electrode angle $30^{\circ}$; $\mathrm{d} 1$-Distance of ionizing electrode and roll surface $40 \mathrm{~mm} ; \theta$ - Static electrode angle $65^{\circ} ; \mathrm{d} 2$ - Distance of static electrode and the electrode $50 \mathrm{~mm} ; \mathrm{n}$ - Roll speed $50 \mathrm{rpm}$; W - Feed rate 30 g.min-1; U - High voltage supply $30 \mathrm{kV}$. The schematic drawing of the electrostatic separator is shown in Figure 2. The CES parameters were based on the study of Hamerski et al. (2019) ${ }^{13}$, where different parameters were evaluated, obtaining these values as being the most efficient condition in the concentration of metals coming from PCBs.

The equipment consists of two electrodes: corona and electrostatic; and a grounded roller. An electromagnetic chute was employed with constant feed rate, generating a thin layer of material that was introduced into the electrostatic field through the spinning roller. One spot was used to collect conductive particles and other two-spots to collect middling and nonconductive by-products.

After the electrostatic separation, a metallic characterization for the conductive and middling fractions was conducted through acid digestion followed by ICP-OES analysis. The samples were digested in $20 \mathrm{ml}$ of aqua regia per gram of solids (1:20) for 2 hours in $60^{\circ} \mathrm{C}$, with agitation speed of $400 \mathrm{rpm}$.

A previous sequence of X-Ray Fluorescence analysis (XRF Thermo Scientific, model Niton XL3t) qualitatively determined the main metallic species presents in the conductive and middling fractions. These main species, plus precious metals (silver and gold), were selected to be quantitatively measured by ICP-OES (Agilent, model 5110).

\section{Results and Discussion}

In this study, the stages of components removal and particle size separation were considered as losses in mass. However, this does not mean that these materials have been lost. Removal of the components was done to avoid damaging the comminution and to have no valuable metals to recover. This procedure was adopted in related works ${ }^{11,14,15,16}$.

At the stage of removal of PCB components there was a losses in mass of $7.7 \%$, the initial mass of $13006 \mathrm{~g}$ had a loss of $1004 \mathrm{~g}$. After processing the material three times in the mechanical milling, the reduction was $378 \mathrm{~g}$, which is equivalent to $2.9 \%$ absolute loss of the initial mass of $\mathrm{PCB}$, and a relative loss of $3.2 \%$. Figure 3 shows all relative losses among the processes. 


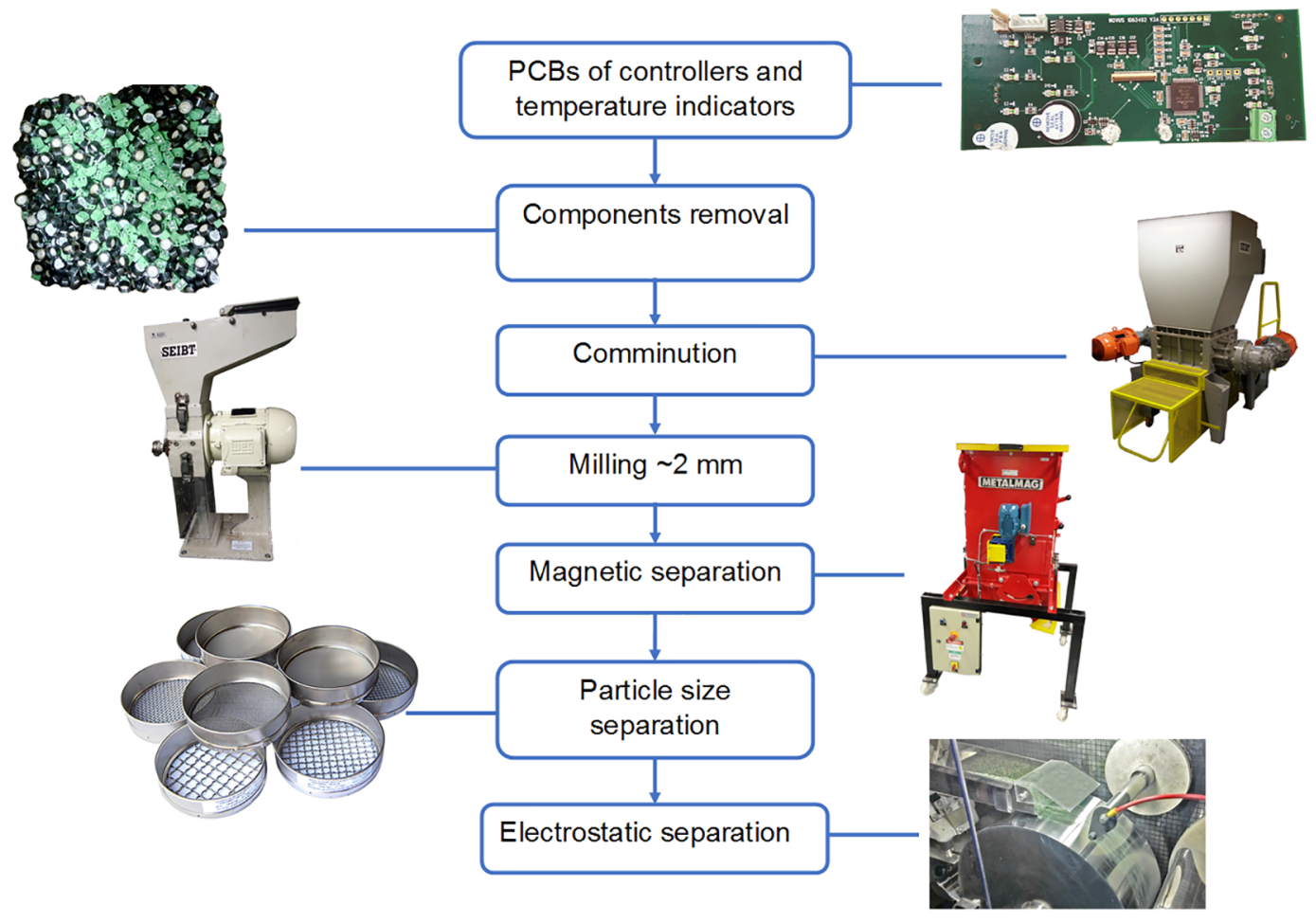

Figure 1. Flowchart of processing steps.

Author: Eduardo Luis Schneider

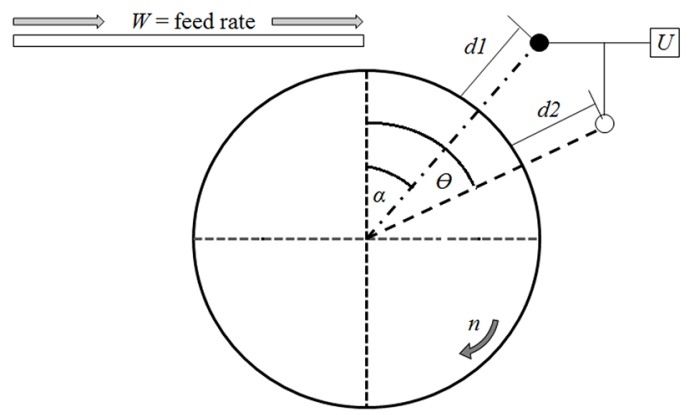

Figure 2. Arrangement of the parameters used in the electrostatic separator. $\alpha$ : ionizing electrode angle; $\mathrm{d} 1$ : distance of ionizing electrode and roll surface; $\theta$ : static electrode angle; $\mathrm{d} 2$ : distance of static electrode and the electrode; $n$ : roll speed; $W$ : feed rate; $U$ : high voltage supply.

Hamerski, et al., 2019.

The grinding step in the knife mill resulted in $204 \mathrm{~g}$ of losses for $8 \mathrm{~mm}$ sieve and $183 \mathrm{~g}$ of losses for $4 \mathrm{~mm}$ sieve (1.7 and $1.6 \%$ relative losses, respectively). After further grinding in the knife mill, this time with a $2 \mathrm{~mm}$ sieve, there was a reduction of $8.3 \%$ relative loss, corresponding to a loss of $889 \mathrm{~g}$.

The magnetic separation process resulted in the division of the sample into a magnetic and a non-magnetic fraction. The magnetic fraction represented by $385 \mathrm{~g}$ of particles

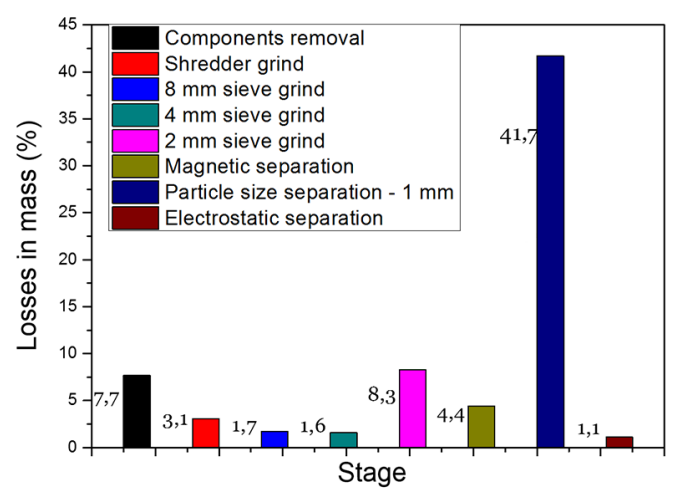

Figure 3. Mass losses of each step. Author: Fernando Hamerski.

and $1535 \mathrm{~g}$ of powder, totaling $17.1 \%$ of PCB amount. The non-magnetic fraction was separated into a portion of powder $(341 \mathrm{~g})$ and a portion of particles $(8481 \mathrm{~g})$, totaling $8822 \mathrm{~g}$ i.e., $78.5 \%$ of initial amount.

Although the efficiency of the processes employed here is not being considered. It is important to compare the amount of obtained material for each fraction (Table 1).

Note that approximately $80 \%$ of the material is fine powder in the magnetic fraction. This large amount of powder after magnetic separation process was also observed in 
Table 1. Magnetic fractions

\begin{tabular}{lcc}
\hline & Magnetic separation & \\
\hline Fraction & $\mathbf{g}$ & $\mathbf{\%}$ \\
\hline Magnetic particle & 385 & 3.4 \\
Magnetic powder & 1535 & 13.7 \\
Magnetic fraction & 1920 & 17.1 \\
Non-magnetic particle & 8481 & 75.5 \\
Non-magnetic powder & 341 & 3 \\
Non-magnetic fraction & 8822 & 78.5 \\
\hline
\end{tabular}

another study, with 1600 Gauss of magnetic field, reaching $70.6 \%$. Hamerski et al. (2018) $)^{17}$ observed that the amount of magnetic materials is much lower than the other materials (e.g. polymers and ceramics). The loading of fine powder into the magnetic collector can explained by the susceptibility of the smaller particles to a high magnetic field, in this study, 4000 Gauss.

We reached out $27.2 \%$ for absolute mass loss after particle size separation with Tyler Series with $1 \mathrm{~mm}$ sieve presents the higher mass losses in the whole process. This fraction with a particle size smaller than $1 \mathrm{~mm}$ was not processed as it results in PCBs powder dust. The PCBs

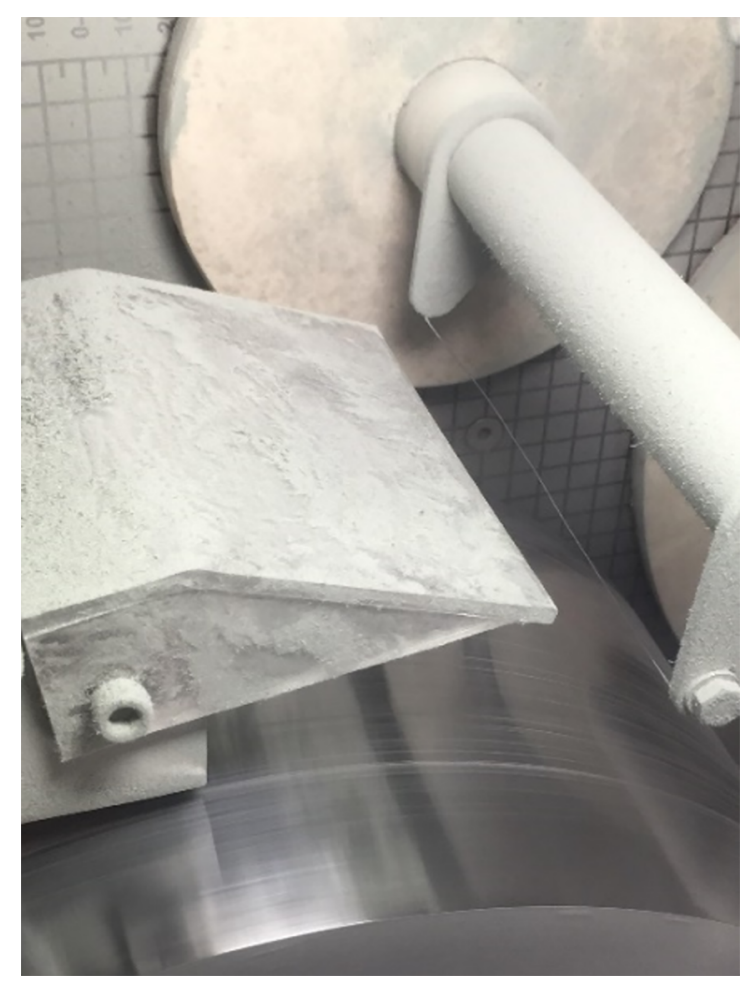

Figure 4. PCB dust accumulation in electrodes. Author: Fernando Hamerski. dust interferes negatively in the electrostatic separation, as shown in Figure 4.

The last stage of the study, the electrostatic separation presents least amount of losses with $0.4 \%$ (absolute). The non-magnetic fraction (1-2 mm) submitted to the electrostatic separator, resulting in three fractions: conductive, intermediate and non-conductive. Figure 5 shows magnetic and non-magnetic fractions as well as conductive and nonconductive fractions.

The data of the quantities of each fraction obtained after the electrostatic separator are in Table 2.

Of the amount that was submitted to the electrostatic separator, $14.8 \%$ constitute the conductive fraction. The middling fraction were $7.7 \%$, corresponding to $380.4 \mathrm{~g}$. The middling fraction is a mixture of conductive and nonconductive material. Conductive material were not varied by the electric field. At the same time, non-conductive material discharges so rapidly and thus disengage from the grounded roller, falling off into the middling material collector.

Conductive fraction represents the most valuable fraction of all processes. The fraction generally contains greater economic value, once high concentration of cooper and other metals are expected. Even the aim is of this work is to evaluate the mass losses, it is opportune to evaluate the metals composition of the conductive and middling fractions, given that studies for PCBs of cold chambers are rare.

The elements $\mathrm{Cu}, \mathrm{Sn}, \mathrm{Pb}, \mathrm{Zn}$ and $\mathrm{Al}$ are the main species found by the XRF analysis in the conductive and middling fractions, and were measured together with Au and Ag in the ICP-OES. The Table 3 demonstrate the metals characterization for the PCBs of cold chambers, comparing with PCBs of other electronic scraps.

The conductive fraction concentrates substantial amounts of $\mathrm{Cu}$ and $\mathrm{Sn}$, respectively $35.54 \%$ and $18.39 \%$ of the total. Indeed, the quantity of $\mathrm{Cu}$ may be enhanced considering the middling fraction, which presented $26.20 \%$ of cooper concentration. $\mathrm{Ag}$ and $\mathrm{Au}$, as precious metals, are present in the PCBs of cold chambers, with similar concentration values to other PCBs (e.g. computers and mobile phones $)^{18}$. 

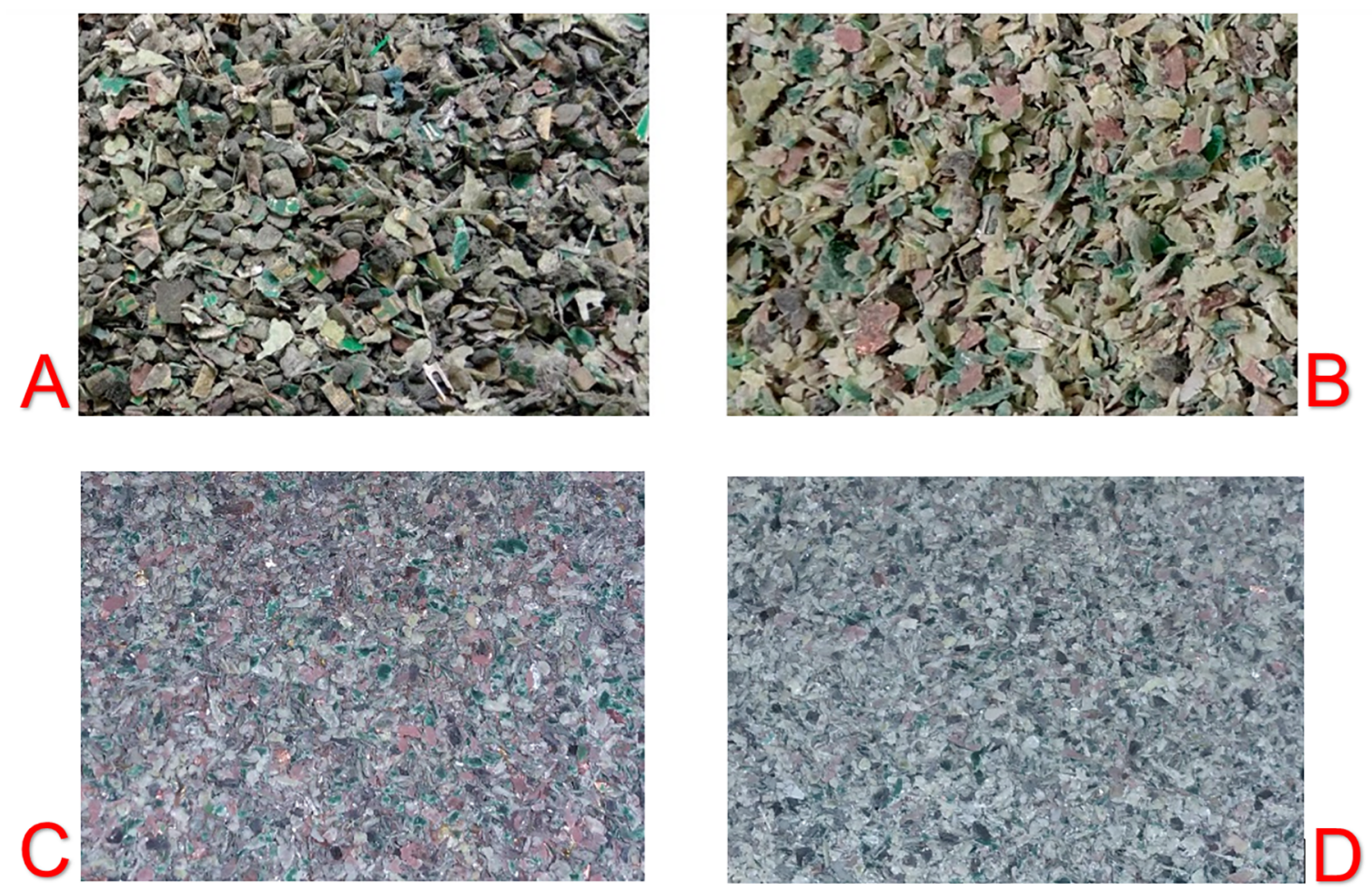

Figure 5. PCB fractions after magnetic and electrostatic separator. A: magnetic; B: non-magnetic; C: conductive; D: non-conductive. Author: Eduardo Luis Schneider.

Table 2. Electrostatic separation fractions

\begin{tabular}{lcc}
\hline & Electrostatic separation & \\
\hline Fraction & g & \% \\
\hline Conductive & 734.1 & 14.8 \\
Middling & 380.4 & 7.7 \\
Non-conductive & 3778 & 76.4 \\
\hline
\end{tabular}

Table 3. Metal characterization for the conductive and middling fractions of different PCBs

\begin{tabular}{lcccccccc}
\hline & & \multicolumn{2}{c}{ Yamane et al. (2011) $^{\mathbf{9}}$} & \multicolumn{2}{c}{ Yamane et al. (2011) $^{\mathbf{9}}$} & Guo et al. (2011) $^{\mathbf{1 7}}$ & Veit et al. (2006) $^{\mathbf{1 8}}$ \\
\hline & \multicolumn{2}{c}{ Cold Chambers } & \multicolumn{2}{c}{ Computers } & \multicolumn{2}{c}{ Mobile Phones } & Computers & Mixed \\
\hline \% & Conductive & Middling & Conductive & Middling & Conductive & Middling & Conductive & Conductive \\
\hline $\mathrm{Cu}$ & 35.54 & 26.20 & 11.17 & 0.58 & 24.32 & 4.09 & 56.29 & 53.04 \\
$\mathrm{Sn}$ & 18.39 & 1.84 & 5.39 & 0.16 & 2.72 & 0.12 & 7.62 & 20.22 \\
$\mathrm{~Pb}$ & 2.11 & 0.32 & 3.29 & 0.09 & 1.39 & 0.08 & 8.24 & 6.42 \\
$\mathrm{Zn}$ & 1.44 & 0.00 & 2.64 & 0.14 & 5.75 & 0.02 & 7.16 & - \\
$\mathrm{Al}$ & 0.91 & 0.94 & 2.41 & 0.15 & 0.20 & 0.01 & 1.04 & - \\
$\mathrm{Ag}$ & 0.13 & 0.07 & 0.05 & 0.00 & 0.16 & 0.01 & - & - \\
$\mathrm{Au}$ & 0.07 & 0.05 & 0.05 & 0.00 & 0.00 & 0.00 & - & - \\
\hline
\end{tabular}

While the conductive and middling fractions correspond to $14.8 \%$ and $7.7 \%$, the non-conductive fraction reached $76.4 \%$ of total amount of non-magnetic fraction. It makes sense that the largest amount of material submitted to the electrostatic separator is non-conductive, since the materials present in greater quantities in PCBs are precisely, nonconductive materials, i.e., polymers and ceramics ${ }^{18,19}$.
The analysis of mass losses is not much discussed in the current literature; therefore, data for comparison of results are scarce, being limited to a few studies that cite losses data in the comminution process ${ }^{9,20}$. A study ${ }^{20}$ involving automotive PCBs industry reported a $20 \%$ loss in mechanical processing. Another study evaluating computer and mobile phones PCBs9 describes a $27 \%$ of losses. 
The analysis of losses in mass in the current study results in $12.7 \%$. This difference is directly relate to the equipment used during the processing of the PCBs. There are different types of mills, with isolated or no collection compartments, continuous sampling or not.

Notes that the results presented only consider the stages of shredding (2.9\% absolute), crushing with $8 \mathrm{~mm}$ sieve (1.6\% absolute), crushing with $4 \mathrm{~mm}$ sieve (1.4\% absolute) and grinding with $2 \mathrm{~mm}$ sieve (6.8\% absolute). The three studies made the removal of components, so that, similarly, they also did not account for this step in the mass losses.

Thus, energy consumption in all steps should be considered in parallel for a real analysis of efficiency to be made.

\section{Conclusions}

This paper evaluated the mass losses at each stage of processing for valuable metal recovery from PCB used in controllers and temperature indicators of cold chambers. We analyzed $13 \mathrm{~kg}$ of PCBs in the comminution and particle size separation, magnetic and electrostatic separation processes. The results shows that it is possible to conclude that the step that proportionally registered the largest mass losses was the particle size process with $1 \mathrm{~mm}$ sieve (Tyler Series). However, this fraction with lower particle size can be reuse, i.e., to develop light aggregates, in partial replacement by volume, to the sand, in cement-based matrices.

Comparing the losses in the stages of shredding of PCBs, in the present study (12.69\%) with other studies involving PCs from the automotive industry $(20 \%)$ and from computers (29\%) and cell phones $(25 \%)$, it is concluded that this type of board presents significantly greater potential to be processed for recovery of its materials.

Additionally, the metals characterization of the conductive and middling fraction of the electrostatic separator demonstrated that PCBs of cold chambers have a great potential for cooper and tin recovery, as these elements reached high concentrations. The precious metals silver and gold presented similar values of concentration to other PCBs (from computers and mobile phones), also signifying a potential for recovery and further studies.

\section{Acknowledgements}

The authors are grateful to Reverse-Gerenciamento de Resíduos Tecnológicos, Novo Hamburgo - RS - Brasil by donating the PCBs used in this study and to Coordenação de Aperfeiçoamento de Pessoal de Nível Superior - Brasil (CAPES/ PROEX 23038.000341/2019-71 0491/2019) for financial support.

\section{References}

1. Gonçalves Neto TJ. Lixo computacional, obsolescência planejada e logistica reversa: relações a desvendar e a aprender [dissertação]. Planaltina (DF): Universidade de Brasília; 2015.

2. SANTANA, E.V.; ELABRAS-VEIGA, L.B. O Estado da Arte da Reciclagem de Resíduos Eletroeletrônicos no Brasil. In: 6 INTERNATIONAL WORKSHOP ADVANCES IN CLEANER PRODUCTION, São Paulo, SP, 2017. Disponível em: http:// www.advancesincleanerproduction.net/sixth/files/sessoes/5A/2/ santana_and_elabras-veiga_academic.pdf. Acesso em: $25 \mathrm{de}$ julho de $201 \overline{8}$.

3. Baldé CP, Forti V, Gray V, Kuehr R, Stegmann P. The global e-waste monitor - 2017. Geneva: United Nations University (ONU); 2017.

4. Wang F, Zhao Y, Zhang T, Duan C, Wang L. Mineralogical analysis of dust collected from typical recycling line of waste printed circuit boards. Waste Management. 2015;43:434-41.

5. Medeiros NM. Caracterização e Separação Física de Placas de Circuito Impresso de Computadores Obsoletos [dissertação]. Natal (RN): Universidade Federal do Rio Grande do Norte; 2015.

6. Ribeiro PPM. Concentração de Metais Contidos Em Placas de Circuito Impresso de Computadores Descartados [dissertação]. Rio de Janeiro (RJ): Universidade Federal do Rio de Janeiro; 2013.

7. Widmer R, Oswald-Krapf H, Sinha-Khetriwal D, Schnellmann M, Böni H. Global perspectives on e-waste. Environmental Impact Assessment Review. 2005;25(5):436-58.

8. Oliveira CR, Bernardes AM, Gerbase AE. Collection and recycling of electronic scrap. A worldwide overview and comparison with the Brazilian situation. Waste Management. 2012;32(8):1592-610.

9. Yamane LH, Moraes VT, Espinosa DCR, Tenório JA. Recycling of WEEE. Characterization of spent printed circuit boards from mobile phones and computers. Waste Management. 2011;31(12):2553-2558.

10. Calgaro CO, Schlemmer DF, Bassaco MM, Dotto GL, Tanabe $\mathrm{EH}$, Bertuol DA. Supercritical extraction of polymers from printed circuit boards using $\mathrm{CO} 2$ and ethanol. Journal of $\mathrm{CO} 2$ Utilization. 2017;22:307-316.

11. Rajagopal RR, Rajarao R, Cholake ST, Sahajwalla V. Sustainable composite panels from non-metallic waste printed circuit boards and automotive plastics. Journal of Cleaner Production. 2017; 144:470-481.

12. Holgersson S, Steenari BM, Björkman M, Cullbrand K. Analysis of the metal content of small-size Waste Electric and Electronic Equipment (WEEE) printed circuit boards - part 1: Internet routers, mobile phones and smartphones. Resources, Conservation and Recycling. 2018;133:300-308.

13. Hamerski F, Krummenauer A, Bernardes AM, Veit HM. Improved settings of a corona-electrostatic separator for copper concentration from wasted printed circuit boards. Journal of Environmental Chemical Engineering. 2019;7(1):102896.

14. Jiang W, Jia L, Zhen-Ming X. A new two-roll electrostatic separator for recycling of metals and nonmetals from waste printed circuit board. Journal of Hazardous Materials. 2009;161(1):257-62. 
15. Kumar A, Holuszko M, Espinosa DCR. E-waste: An overview on generation, collection, legislation and recycling practices. Resources, Conservation and Recycling. 2017;122:32-42.

16. Estrada-Ruiz RH, Flores-Campos R, Gámez-Altamirano HA, Velarde-Sánchez EJ. Separation of the metallic and non-metallic fraction from printed circuit boards employing green technology. Journal of Hazardous Materials. 2016;311:91-99.

17. Hamerski F, Bernardes DP, Veit HM. Operational conditions of an electrostatic separator for concentrate copper from electronic waste. REM - International Engineering Journal. 2018;71(3):431-436.
18. Veit HM, Bernardes AM, Ferreira JZ, Tenório JA, Malfatti CF. Recovery of copper from printed circuit boards scraps by mechanical processing and electrometallurgy. Journal of Hazardous Materials. 2006;137(3):1704-9.

19. Guo C, Wang H, Liang W, Fu J, Yi X. Liberation characteristic and physical separation of printed circuit board (PCB). Waste Management. 2011;31(9-10):2161-2166.

20. Cucchiella F, D’Adamo I, Rosa P, Terzi S. Automotive printed circuit boards recycling: an economic analysis. Journal of Cleaner Production. 2016;121:130-141. 